\title{
Subacute Longitudinal Myelitis Associated with Behcet's Disease
}

\author{
Jiro Fukae ${ }^{1}$, Kazuyuki Noda ${ }^{1}$, Kenji Fujishima ${ }^{1}$, Toshiyuki Takahashi ${ }^{2}$, Nobutaka Hattori ${ }^{3}$ \\ and Yasuyuki Okuma ${ }^{1}$
}

\begin{abstract}
In neuro-Behcet's disease (NBD), myelitis is a rare clinical form. We report the case of a woman with NBD presenting with unsteady gait and generalized spasticity. Spinal magnetic resonance imaging (MRI) showed multiple and confluent hyperintensities extending throughout the entire spinal cord on a T2-weighted image with some contrast enhancement. High-dose steroid therapy was so effective that the myelitis was markedly improved, as shown in the follow-up MRI. Longitudinal myelitis involving the entire spinal cord, as seen in our patient, has never been described before. This case suggests that NBD could be one of the important differential diagnoses of longitudinal myelitis.
\end{abstract}

Key words: neuro-Behcet's disease, myelitis, long cord lesion, MRI, corticosteroid, elderly

(Inter Med 49: 343-347, 2010)

(DOI: 10.2169/internalmedicine.49.2175)

\section{Introduction}

Behcet's disease (BD) is a chronic, relapsing inflammatory disorder of unknown etiology, characterized by a triad of recurrent aphthous stomatitis, genital ulceration, and uveitis (1). BD incidence is significantly higher in Mediterranean, Middle East, and East Asian countries. It is now known that BD involves various organs such as those of the cardiovascular, pulmonary, gastrointestinal, musculoskeletal, and central nervous systems (CNS). Several large studies have revealed that the neurological complication of $\mathrm{BD}$, termed neuro-Behcet's disease (NBD), occurs in approximately $5-49 \%$ of patients with BD (1-4). Although lesions of the brainstem and basal ganglia are most commonly associated with NBD, spinal cord involvement is very rare (3-8). Here, we report the first case of subacute longitudinal myelitis affecting the entire spinal cord in an elderly woman.

\section{Case Report}

A 65-year-old woman presented with loss of appetite and a gradual decrease in body weight. Two months later, she complained of increasing difficulty in walking and weakness in her upper limbs. She noticed recurrent oral ulcers six months prior to admission. For further study, she was admitted to our hospital in October 2006. She had no familial history of neurological disorders.

On admission, her body temperature was $36.3^{\circ} \mathrm{C}$. She had multiple oral ulcerations but no abnormal skin lesions and genital ulceration. Bilateral uveitis was found upon ophthalmological examination. The pathergy test was performed by pricking the skin of the flexor surface of the forearm with a disposable needle. Within 48 hours, the formation of a papule was observed. On neurological examination, she was alert and mentally sound. Her higher cerebral functions and all her cranial nerves were intact. She had mild spastic quadriplegia and was not able to walk without assistance. Her deep tendon reflexes were brisk in both her upper and lower limbs and she showed the head retraction reflex. Pathological reflexes such as the Hoffmann and Babinski signs were present bilaterally. Her sensory and autonomic nervous systems were intact.

Routine hematological tests showed mild pancytopenia. Results of her routine biochemical tests, including her Creactive protein level, were within the normal ranges. Viral

${ }^{1}$ Department of Neurology, Juntendo University Shizuoka Hospital, Shizuoka, ${ }^{2}$ Department of Neurology, Tohoku University School of Medicine, Sendai and ${ }^{3}$ Department of Neurology, Juntendo University School of Medicine, Tokyo

Received for publication February 18, 2009; Accepted for publication October 18, 2009

Correspondence to Dr. Yasuyuki Okuma, sgz02202@nifty.ne.jp 

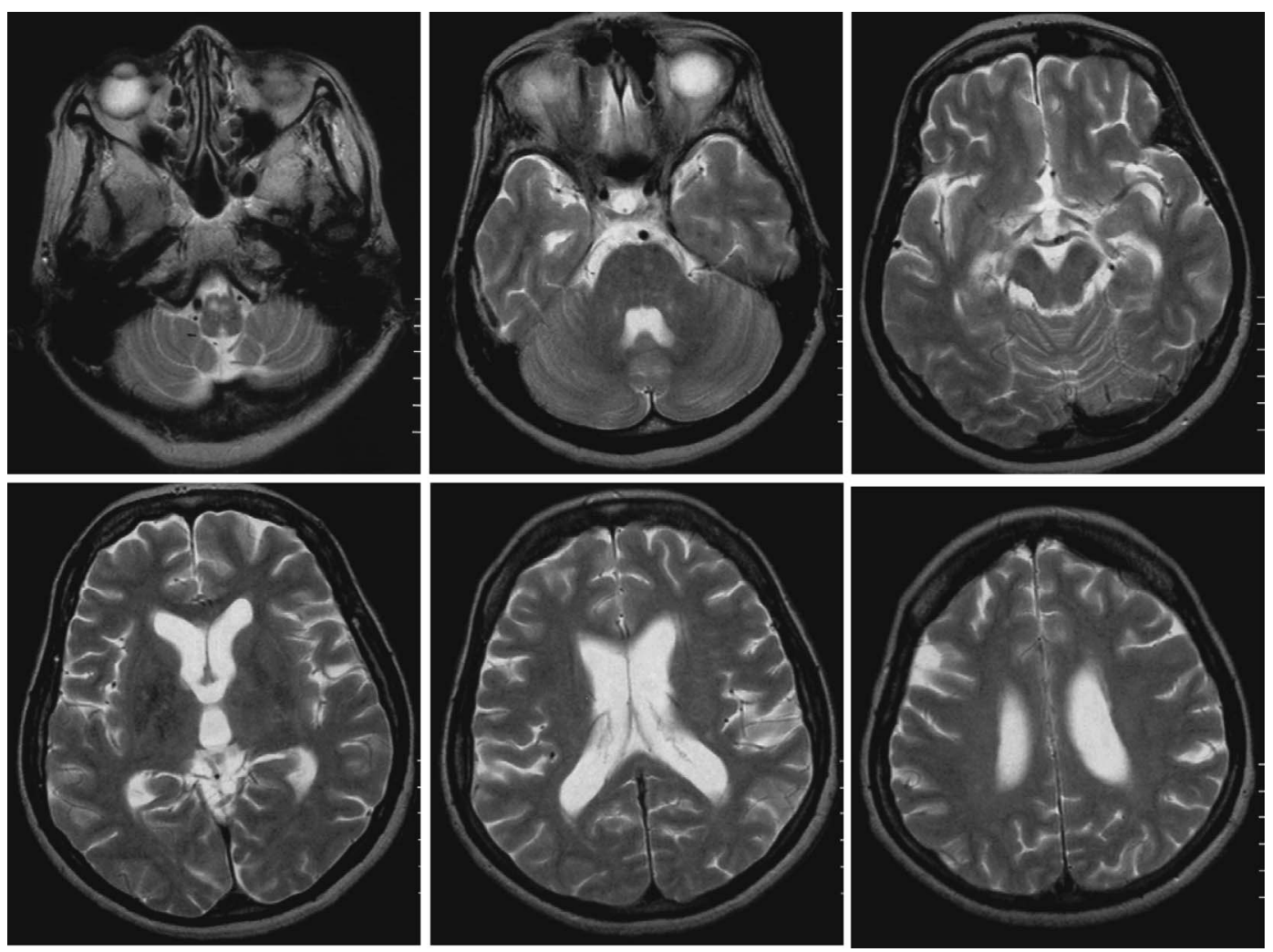

Figure 1. T2-weighted brain MR images showed a high signal intensity in the lower part of the medulla oblongata. There were no abnormal lesions in the pons, midbrain, basal ganglia, subcortical white matter, or cerebral cortex.

serology (herpes simplex virus, herpes zoster virus, and human T-cell lymphotropic virus type 1) showed negative findings. Serological examinations revealed that she was negative for anti-nuclear antibodies (ANA), anti-SSA, and antiSSB antibodies, and MPO-ANCA. The levels of the angiotensin-converting enzyme (ACE) and the complement components $\mathrm{C} 3$ and $\mathrm{C} 4$ were within the normal ranges. She was negative for neuromyelitis optica (NMO)-IgG. The vitamin $\mathrm{B}_{12}$ and $\mathrm{IgD}$ levels were also within the normal range. Bone marrow examination showed no abnormal findings indicative of hematological malignancy such as lymphoma. Human leukocyte antigen (HLA) typing showed that she had B51 and B44. Her cerebrospinal fluid (CSF) contained 39 cells $/ \mu \mathrm{L}$ (35 lymphocytes and 4 neutrophils), $56 \mathrm{mg} / \mathrm{dL}$ glucose, and $144 \mathrm{mg} / \mathrm{dL}$ protein. Her IgG index was 0.66 , and oligoclonal bands were not detected. Cultures of her CSF yielded no bacterial growth. Tuberculosis DNA was not detected in her CSF.

Cranial magnetic resonance imaging (MRI) showed increased signal intensity in the lower part of the medulla oblongata on T2-weighted and FLAIR images (Fig. 1). There were no abnormal lesions in the pons, midbrain, basal ganglia, subcortical white matter, or cerebral cortex (Fig. 1). Spinal MRI showed multiple and confluent hyperintensities within the entire spinal cord on T2-weighted images (Fig. 2A). On the axial images, hyperintensity was mostly observed in the central gray matter. The axial extension of the lesions varied depending on the spinal level and the le- sions extended to the lateral column in some levels. At the medulla and medullospinal junction levels, hyperintensity was observed in the ventral part, which involved the pyramidal tract. These spinal cord lesions were mildly enhanced with gadolinium on T1-weighted images (Fig. 2B). On the axial images, however, the area of gadolinium enhancement was less extensive as compared with that observed on T2weighted images. There were no abnormal findings on chest and abdominal computed tomography (CT), and on gastrointestinal and colon fiber examination. On the basis of the results of physical, serological, and neuroradiological examinations, she was diagnosed as having myelitis associated with $\mathrm{BD}$, because she fulfills the BD criteria proposed by the International Study Group (9). Intravenous methylprednisolone $(1,000 \mathrm{mg} / \mathrm{day})$ was administered for three days, followed by an oral administration of prednisolone $(60 \mathrm{mg} / \mathrm{day})$. Then, the administration of prednisolone was gradually tapered by $10 \mathrm{mg}$ per week and was reduced to $30 \mathrm{mg} / \mathrm{day}$ at discharge. Her clinical symptoms were markedly improved within two weeks. She was able to walk without assistance by the time she was discharged from our hospital. At one year after her discharge, she is still taking prednisolone (20 mg/every other day) and her walking remains stable. Her oral ulcers disappeared, and abnormal skin lesion and genital ulcer were not observed throughout the course of follow-up. Spinal cord MRI at this time was normal (Fig. 2C). 

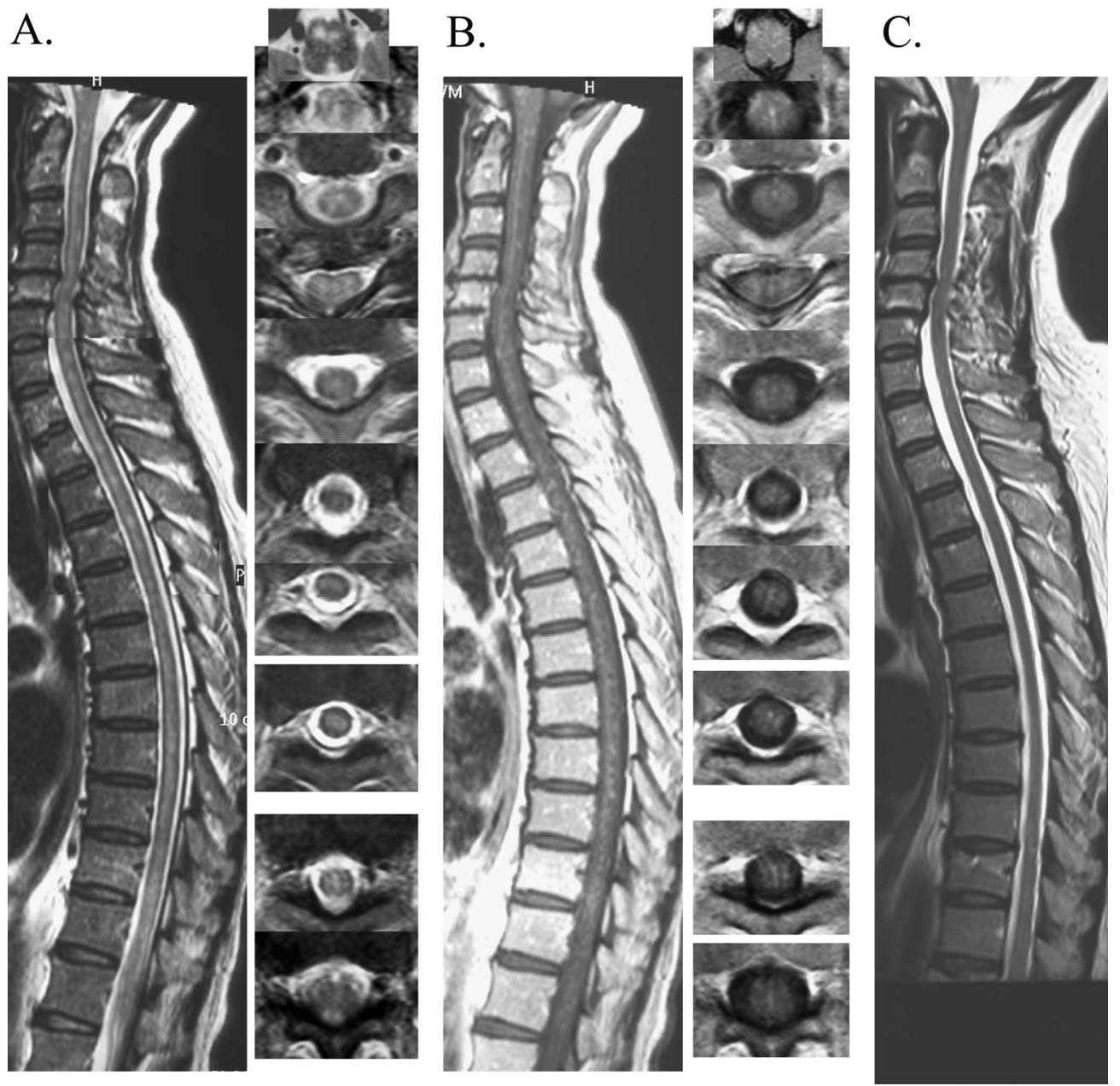

Figure 2. T2-weighted spinal cord MR image showed slightly swollen cord and hyperintensities within the entire spinal cord (A). Axial images revealed a hyperintensity predominantly in the central gray matter that extended to the white matter in some levels. A hyperintensity was also observed in the ventral part at the medulla oblongata and medullocervical junction levels. T1-weighted post-contrast images showed mild high intensities along the entire spinal cord (B). On the axial images, the area of enhancement was less extensive than that observed on T2weighted images. A T2-weighted image taken one year after the discharge was normal (C).

\section{Discussion}

Because BD does not have any pathognomonic symptoms or laboratory findings, diagnosis is made on the basis of the criteria proposed by the International Study Group for BD $(1,9)$. According to the criteria, recurrent oral ulceration must be present and accompanied by two of the following: recurrent gential ulceration, eye lesions, skin lesions, and a positive pathergy test (9). Our patient had oral ulceration, uveitis, and positive pathergy test and fulfilled the BD criteria of the International Study Group. Therefore, we concluded that her myelitis was associated with BD. Although myelitis is caused by many other diseases, such as NMO, multiple sclerosis (MS), CNS lupus, infection, acute disseminated encephalomyelitis, CNS lymphoma, paraneoplastic syndrome, and subacute combined degeneration, laboratory data excluded all these diseases.

In NBD, several clinical studies have suggested that the most commonly affected region is the brainstem, while spinal cord involvement is rare, ranging from 0 to $14 \%$ of NBD patients $(3-8,10)$. Indeed, case reports describing NBD with myelitis remain rare and only eight cases have been reported with their clinical courses and MRI findings described in detail in the English language literature (Table 1) in addition to the recently published series of studies $(5,10-17)$. The spinal MRI of those patients showed noncontiguous multifocal high-intensity signals on T2weighted images with some contrast enhancement in the acute or subacute phase. In the chronic phase, the lesions showed slightly high-intensity signals on T2-weighted images without enhancement, and the sizes of the lesions decreased with or without atrophy (11-18). These findings are consistent with those of the present patient. However, the most notable finding in our patient was the extensive distribution of the lesions. Although myelitis associated with NBD shows relatively long lesions (11-18), there has been no report describing NBD patients with whole spinal cord 
Table 1. Clinical Course of Neuro-Behcet's Disease with Spinal Cord Involvement in the English Literature

\begin{tabular}{|c|c|c|c|c|c|c|c|c|}
\hline Authors & Age & Sex & First symptoms & $\begin{array}{c}\text { MRI } \\
\text { findings }\end{array}$ & $\begin{array}{l}\text { Site } \\
\text { of } \\
\text { lesions }\end{array}$ & $\begin{array}{c}\text { Length } \\
\text { (segments) }\end{array}$ & Treatment & Outcome \\
\hline $\begin{array}{c}\text { Lannuzel et al. [5], } \\
2002\end{array}$ & 19 & $\mathrm{~F}$ & $\begin{array}{l}\text { Hyperthermia } \\
\text { tetraplegia }\end{array}$ & T2:high & $\mathrm{C} 1-\mathrm{C} 4$ & 4 & $\begin{array}{c}\text { cyc(iv) } \\
\rightarrow \\
\operatorname{aza}(\mathrm{o})+\operatorname{steroid}(\mathrm{o})+\operatorname{col}(\mathrm{o})\end{array}$ & $\begin{array}{c}\text { Not } \\
\text { improved }\end{array}$ \\
\hline $\begin{array}{l}\text { Morrissey et al. [11], } \\
1993\end{array}$ & 56 & M & - & $\begin{array}{l}\text { T1:iso, T2:high } \\
\text { atrophy }\end{array}$ & BS-C5 & 6 & NA & NA \\
\hline $\begin{array}{c}\text { Yoshioka et al. [12], } \\
1996\end{array}$ & 10 & M & paraparesis & $\begin{array}{l}\text { T1:iso, T2:high } \\
\text { Gd(+) }\end{array}$ & $\begin{array}{l}\mathrm{C} 5-\mathrm{C} 7 \\
\mathrm{~T} 5-\mathrm{T} 7\end{array}$ & $\begin{array}{l}3 \\
3\end{array}$ & NA & $\begin{array}{c}\text { Not } \\
\text { improved }\end{array}$ \\
\hline $\begin{array}{c}\text { Mascalchi et al. [13], } \\
1998\end{array}$ & 35 & F & Gait disurbance & $\begin{array}{l}\text { T2:high } \\
\mathrm{Gd}(+)\end{array}$ & T6-T8 & 3 & steroid(iv) $\rightarrow$ cyc(iv) & $\begin{array}{l}\text { Relapsed in } \\
\text { BS and FL }\end{array}$ \\
\hline $\begin{array}{l}\text { Green et al. [14], } \\
2000\end{array}$ & 40 & M & anaesthesia & $\begin{array}{l}\text { T1:iso-hypo, } \\
\text { T2:high, Gd(+) }\end{array}$ & $\mathrm{C} 2-\mathrm{C} 5$ & 4 & $\mathrm{MP}(\mathrm{iv}) \rightarrow$ PSL (o) & improved \\
\hline $\begin{array}{l}\text { Lee et al.[15], } \\
\qquad 2001\end{array}$ & 26 & M & Gait disurbance & $\begin{array}{l}\text { T2:high } \\
\text { Gd(+) }\end{array}$ & T4-T11 & 8 & NA & NA \\
\hline $\begin{array}{l}\text { Moskau et al. [16], } \\
2003\end{array}$ & 26 & M & paraparesis & $\begin{array}{l}\text { T2:high } \\
\text { Gd(+) }\end{array}$ & $\mathrm{C} 2-\mathrm{T} 6$ & 12 & $\begin{array}{c}\mathrm{MP}(\mathrm{iv}) \\
\rightarrow \mathrm{PSL}(\mathrm{o})+\mathrm{aza}(\mathrm{o})\end{array}$ & improved \\
\hline $\begin{array}{l}\text { Calguneri et al.[17], } \\
2005\end{array}$ & 24 & M & Paresthesia & T2:high & T6 & 1 & $\begin{array}{c}\text { steroid(o) } \\
\rightarrow \\
\text { MP(iv)+cyc(iv)+IFN(iv) }\end{array}$ & improved \\
\hline Our case & 65 & $\mathrm{~F}$ & Gait disurbance & $\begin{array}{l}\text { T1:iso-hypo, } \\
\text { T2:high, Gd(+) }\end{array}$ & BS-L2 & entire & $\mathrm{MP}(\mathrm{iv}) \rightarrow \mathrm{PSL}(\mathrm{o})$ & improved \\
\hline
\end{tabular}

MRI, magnetic resonance imaging; M, male; F, female; T1, T1 weighted image; T2, T2 weighted image; Gd(+),enhancement with gadolinium; C, cervical; T, thoracic, NA, not available; iv, intravenous; o, oral;MP, methylprednisolone PSL,prednisolone; cyc, cyclophosphamide; IFN, interferon; Aza, azathioprine; Co, colchicine; BS, brainstem; FL, frontal lobe.

involvement. Recently, a longitudinally extensive spinal cord lesion has been reported in a case of NBD, but the patient showed the lesion from $\mathrm{C} 1$ to Th3 spinal levels (19). Therefore, our patient is the first to show longitudinal myelitis involving the entire spinal cord together with medulla oblongata lesions.

The pathophysiology of a long cord lesion is still unknown. Autopsy and biopsy studies suggest that venous vasculitis play an important role in the pathogenesis of NBD (18). In the spinal cord, the intrinsic venous system consists of an extensive network that interconnects with numerous vertical and transmedullary anastomotic channels. Small veins finally connect to the anterior or posterior spinal veins, which run longitudinally along the spinal cord surface. It is possible that small-vessel obstructions due to vasculitis at multiple sites along the spinal veins induce stagnation and edema mainly in the central gray matter longitudinally. Any further discussion beyond this level seems to be highly speculative.

Despite the extensive spinal cord lesions, our patient showed only mild spastic quadriplegia without sensory or sphincter disturbances. Pyramidal signs can be partly explained by lesions in the medulla oblongata, but there was some clinico-radiological dissociation. One possibility is that the long spinal cord lesions on MR images may largely reflect inflammation and edema, without necrosis, induced by venous vasculitis and stagnation, because she showed a good response to corticosteroid therapy. The fact that no permanent signal changes were seen in the follow-up spinal cord MRI may support this hypothesis. A similar clinicoradiological dissociation was observed in the patient recently reported by Takechi and colleagues (19).

Another interesting finding in the present patient was the old-age onset of the disease. According to previous case series, the mean age of first neurological presentation in NBD patients ranged from 31 to 37.5 years $(3,4,6-8,10,11)$. An age at onset above 60 years is quite unusual. Recently, Yesilot et al reviewed the cases of 24 NBD patients with spinal cord involvement (10). The mean age at NBD onset was also young ( $34 \pm 12$ years), and only one of the 24 patients presented neurological symptoms at an age above 60 years. They also showed that age at NBD onset did not significantly differ between those with spinal cord lesions and those without (10). The present patient seems to be the oldest NBD patient with myelitis, and this suggests that NBD is one of the important differential diagnoses of longitudinal myelitis even in elderly patients.

Because most NBD patients with spinal cord involvement tend to show a primary or secondary progressive course, their prognosis is worse than those with other types of NBD (10). There is no established treatment protocol for NBD myelitis. In most NBD patients with myelitis, highdose systemic corticosteroid therapy was reported to be effective for the acute or subacute phase $(1,11-13,19)$. However, there were some reports describing patients who showed a poor response to corticosteroid ther- 
apy $(5,10,13,16,17)$. In those patients, other immunosuppressants or interferon $\alpha$ may be used $(1,10,17)$. Although our patient had extensive lesions within the entire spinal cord, she showed an excellent response to corticosteroid therapy, and no recurrence was observed within the one-year follow-up period. We hypothesize that early commencement of corticosteroid therapy was beneficial for our patient despite the long spinal cord lesions. In conclusion, although rare, NBD should be considered even in elderly patients with longitudinal myelitis.

\section{References}

1. Sakane T, Takeno M, Suzuki N, Inaba G. Behcet's disease. N Engl J Med 341: 1284-1291, 1999.

2. Stratigos AJ, Laskaris G, Sratigos JD. Behcet's disease. Semin Neurol 12: 346-357, 1992.

3. Akman-Demir G, Serdaroglu P, Tasci B. Clinical patterns of neurological involvement in Behcet's disease: evaluation of 200 patients. Brain 122: 2171-2182, 1999.

4. Kidd D, Steuer A, Denman AM, Rudge P. Neurological complications in Behcet's syndrome. Brain 122: 2183-2194, 1999.

5. Lannuzel A, Lamaury I, Charpentier D, Caparros-Lefebvre D. Neurological manifestation of Behcet's disease in Caribbean population: clinical and imaging findings. J Neurol 249: 410-418, 2002.

6. Ashjazadeh N, Borhani Haghighi A, Samangooie Sh, Moosavi H. Neuro-Behcet's disease: a masquerader of manifestations of Behcet's disease in 96 Iranian patients. Exp Mol Pathol 74: 17-22, 2003

7. Al-Araji A, Sharquie K, Al-Rawi Z. Prevalence and patterns of neurological involvement in Behcet's disease: a prospective study from Iraq. J Neurol Neurosurg Psychiatry 74: 608-613, 2003.

8. Joseph FG, Scolding NJ. Neuro-Behcet's disease in Caucasians: a study of 22 patients. Eur J Neurol 14: 174-180, 2007.

9. International Study Group for Behcet's Disease. Criteria for diagnosis of Behcet's disease. Lancet 335: 1078-1080, 1990.

10. Yesilot N, Mutlu M, Gungor O, Baykal B, Serdaroglu P, AkmanDemir G. Clinical characteristics and course of spinal cord in- volvement in Behcet's disease. Eur J Neurol 14: 729-737, 2007.

11. Morrissey SP, Miller DH, Hermaszewski R, et al. Magnetic resonance imaging of the central nervous system in Behcet's disease. Eur Neurol 33: 287-293, 1993.

12. Yoshioka H, Matsubara T, Miyanomae Y, Kawase S, Akioka S, Sawada T. Spinal cord MRI in neuro-Behcet's disease. Neuroradiology 38: 661-662, 1996.

13. Mascalchi M, Cosottini M, Cellerini M, Paganini M, Arnetoli G. MRI of spinal cord involvment in Behcet's disease: case report. Neuroradiology 40: 255-257, 1998.

14. Green AL, Mitchell PJ. Spinal cord Neurobehcet's disease detected on magnetic resonance imaging. Australas Radiol 44: 201203, 2000.

15. Lee SH, Yoon PH, Park SJ, Kim DI. MRI findings in neuroBehcet's disease. Clin Radiol 56: 485-494, 2001.

16. Moskau S, Urbach H, Hartmann A, Schmidt S. Multifocal myelitis in Behcet's disease. Neurology 60: 517, 2003.

17. Calguneri M, Onat AM, Ozturk MA, et al. Transverse myelitis in a patient with Behcet's disease: favorable outcome with a combination of interferon-alpha. Clin Rheumatol 24: 64-66, 2005.

18. Kocer N, Islak C, Siva A, et al. CNS involvement in neuroBehcet's syndrome: an MR study. Am J Neuroradiol 20: 10151024, 1999.

19. Takechi U, Okada K, Uozumi T, Tsuji S. Longitudinally extensive spinal cord lesion in a case of Neuro-Behcet disease. Rinsho Shinkeigaku 48: 48-51, 2008 (in Japanese).

(C) 2010 The Japanese Society of Internal Medicine http://www.naika.or.jp/imindex.html 